\title{
Allylic $\mathrm{sp}^{3} \mathrm{C}-\mathrm{H}$ borylation of alkenes via allyl-Pd intermediates: an efficient route to allylboronates $\dagger$
}

Cite this: Chem. Commun., 2014, 50, 9207

Received 30th May 2014,

Accepted 26th June 2014

DOI: $10.1039 / c 4 c c 04151 \mathrm{~h}$

www.rsc.org/chemcomm

\author{
Hong-Ping Deng, ${ }^{a}$ Lars Eriksson ${ }^{b}$ and Kálmán J. Szabó*a
}

\begin{abstract}
Palladium catalyzed allylic $\mathrm{C}-\mathrm{H}$ functionalization was performed using exocyclic alkene substrates. Multi-component synthesis of stereodefined homoallylic alcohols could be performed using a reaction sequence involving allylic $\mathrm{C}-\mathrm{H}$ borylation and allylation of aldehydes.
\end{abstract}

Catalytic C-H borylation has become a practically useful synthetic method for preparation of organoboronates. ${ }^{1}$ The main reason is that these transition metal catalyzed $\mathrm{C}-\mathrm{H}$ functionalization reactions can be performed under relatively mild conditions with remarkably high selectivity ${ }^{1 b, c}$ usually using $\mathrm{B}_{2} \mathrm{Pin}_{2}$ as a boronate source. The largest efforts have been focused on $\mathrm{sp}^{2} \mathrm{C}-\mathrm{H}$ borylation of aromatic and alkene substrates to obtain aryl/heteroaryl ${ }^{2}$ and vinyl ${ }^{3}$ boronates. However, in the last couple of years increased attention has been focused on development of $\mathrm{sp}^{3} \mathrm{C}-\mathrm{H}$ functionalization methods. ${ }^{4}$ These studies involved functionalization of aliphatic $\mathrm{C}-\mathrm{H}$ bonds ${ }^{4 d-h, l, m, o-q}$ usually directed by heteroatoms, benzylic $\mathrm{C}-\mathrm{H}$ bonds ${ }^{4 i-k}$ and there are a few examples of allylic $\mathrm{C}-\mathrm{H}$ borylation ${ }^{4 a-c}$ as well. A selective allylic $\mathrm{C}-\mathrm{H}$ borylation ${ }^{4 a-c}$ is particularly challenging to achieve due to two main reasons: (i) under catalytic conditions allylboronates very easily rearrange to the more stable vinylboronates. ${ }^{3 b, c, f, 4 c}$ Thus, even if the kinetic product is an allylboronate, the thermodynamic (final) product of the $\mathrm{C}-\mathrm{H}$ borylation of alkenes is vinylboronate; i.e. an overall $\mathrm{sp}^{2}$ instead of $\mathrm{sp}^{3} \mathrm{C}-\mathrm{H}$ bond functionalization; and (ii) for non-symmetrical organometallic intermediates (e.g. allyl or alkylmetal species) the regioselectivity of the borylation is difficult to control. Therefore, only a very few transition metal catalyzed methods are available for allylic $\mathrm{C}-\mathrm{H}$ borylation of alkenes ${ }^{4 a-c}$ and because of (i) and (ii) the substrate scope is also very narrow.

The previously developed procedures providing predominantly allylboronate products are based on $\mathrm{C}-\mathrm{H}$ functionalization of simple cycloalkenes (Fig. 1). Sabo-Etienne and Caballero ${ }^{4 a}$ have shown that

\footnotetext{
${ }^{a}$ Department of Organic Chemistry, Stockholm University, Sweden

${ }^{b}$ Department of Inorganic and Structural Chemistry, Stockholm University, Sweden. E-mail:kalman@organ.su.se; Web: http://www.organ.su.se/ks/; Fax: +46-8-15 4908

$\dagger$ CCDC 1000349. For crystallographic data in CIF or other electronic format see DOI: $10.1039 / \mathrm{c} 4 \mathrm{cc} 04151 \mathrm{~h}$
}

a)

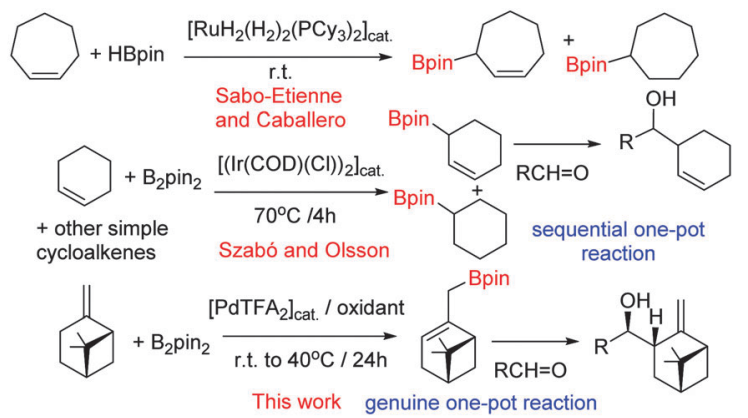

Fig. 1 Overview of catalytic allylic $\mathrm{C}-\mathrm{H}$ borylations.

cycloheptene undergoes hydroboration and allylic $\mathrm{C}-\mathrm{H}$ borylation in the presence of catalytic amounts of bis(dihydrogen)Ru complex. We have $\operatorname{shown}^{4 b, c}$ that simple cycloalkenes can be reacted with $\mathrm{B}_{2} \mathrm{pin}_{2}$ in the presence of Ir-catalysts to give allyl-Bpin compounds.

Interestingly, other catalytic conditions with the above endo-cyclic alkene substrates using rhodium ${ }^{3 g}$ or palladium ${ }^{3 c, f}$ catalysts also give allyl-Bpin products in varying amounts. However, for substrates with an exo-cyclic double bond allylic $\mathrm{C}-\mathrm{H}$ borylation has never been reported. This can probably be explained by the mechanistic features of the currently available $\mathrm{Ru}, \mathrm{Rh}$, Ir and Pd catalyzed methods. In all cases initial formation of an M-Bpin complex can be postulated (eqn (1)), which undergoes a syn insertion into the double bond followed by a syn selective $\beta$-hydride elimination. However, acyclic compounds can undergo unhindered rotation of the $\sigma$-bonds, and therefore the $\beta$-hydride elimination may easily result in the thermodynamically more stable vinyl-Bpin form. ${ }^{4 c}$

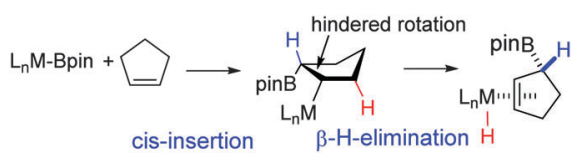

Therefore, we decided to develop a new $\mathrm{sp}^{3}$ allylic $\mathrm{C}-\mathrm{H}$ borylation reaction based on an alternative mechanistic concept. We hypothesized that a Pd-catalyzed process based on initial formation of an allyl-Pd complex followed by transmetallation ${ }^{5}$ with $\mathrm{B}_{2} \mathrm{pin}_{2}$ may 
avoid the termination of the reaction with $\beta$-hydride elimination. The realization of this idea is very challenging, as closing the catalytic cycle (see bellow) requires use of oxidants, while $\mathrm{B}_{2} \mathrm{pin}_{2}$ is a reductant and allylboronates are sensitive to oxidation. ${ }^{6}$

We directed the initial studies to $\mathrm{C}-\mathrm{H}$ functionalization of $\beta$-pinene 1a, as these compounds readily form ${ }^{7}\left(\eta^{3}\right.$-allyl)palladium complexes with stoichiometric amounts of Pd-salts. Indeed, when 1a, 3a, an appropriate oxidant and catalytic amounts of Pd(TFA $)_{2}$ were mixed in $\left(\mathrm{CD}_{3}\right)_{2} \mathrm{CO}$, formation of borylated $\beta$-pinene was observed (Fig. 1c). Using deuterated acetone enabled us to follow the reaction by ${ }^{1} \mathrm{H}$ NMR. The ${ }^{1} \mathrm{H}$ NMR of the reaction mixture showed that the reaction was not completed, probably because of product inhibition. When the allylboronate product was quenched with nitro-benzaldehyde (2), the corresponding homoallylic alcohol 4a was formed selectively as a single, regio-stereoisomer.

Gratifyingly, the entire procedure with 1a, 2, 3a, the oxidant (BQ), TFA and the Pd-catalyst could be performed as a multi-component ${ }^{8}$ (or genuine one-pot) reaction (Table 1, entry 1). As we used optically active $\beta$-pinene, the multicomponent $\mathrm{C}-\mathrm{H}$ borylation-allylation sequence gave an enantiomerically pure product (4a). The structure of 4a was assigned on the basis of single crystal X-ray diffraction. Subsequently, we studied the synthetic scope of the reaction. We have found that cyclic substrates with an exocyclic double bond give synthetically useful yields in the $\mathrm{C}-\mathrm{H}$ borylation based allylation of aldehydes (Table 1). In most cases (except 1a) we obtained complex mixtures and low yields, when we used BQ as an oxidant. However, 2,6-dimethyl BQ (DMBQ) successfully replaced BQ. Deuterated acetone proved to be an ideal solvent in most cases as it allowed us to study the crude mixtures by ${ }^{1} \mathrm{H}$ NMR. In some cases, the process was slow in acetone (e.g. entries 4-6 and 10) and therefore the solvent was changed to trifluoro toluene, which gave a higher reaction rate.

Nitro-benzaldehyde 2 could be replaced by benzaldehyde or aliphatic aldehyde (entries 2 and 3). The multicomponent reaction is still very selective but the yield was dropped ( $c f$. entries 1-3). The reaction with six-membered ring based substrates $\mathbf{1 b}-\mathbf{d}$ gave exclusively the branched allylic products $4 \mathbf{d}-\mathbf{e}$ (entries 4 and 5). There are three stereogenic carbons in product $\mathbf{4 f}$, thus statistically four diastereomers could be formed. However, the reaction proceeds with a remarkably high stereoselectivity, as only two diastereomers were obtained in a ratio of 9:1 (entry 6). The reactions for the five membered ring based substrate 1e proceeded faster than for the six membered ring analogs, and therefore the reactions could be conducted at rt. The best yield and selectivity were obtained, when DMBQ was replaced by tetramethyl BQ as an oxidant (entry 7). The seven membered ring based substrate 1f reacted with high yield (entry 8 ) but the regioselectivity was also lower than for the six-membered ring based substrates. In the case of $1 \mathrm{~g}$ containing an eight-membered ring the regioselectivity drops to $2.5: 1$ (entry 9). We had a limited success with borylation of heterocyclic substrates, such as $\mathbf{1 h}$ (entry 10). This compound can also be transformed into $\mathbf{4 j}$ with high selectivity but the yield is poor and we could not improve it by extensive optimization. For acyclic analogs the yield and the selectivity drop dramatically (entry 11). For example 1i reacts very slowly and with low conversion probably because of inhibition of the Pd-catalyst. Interestingly,
Table 1 Allylic C-H borylation of alkenes ${ }^{a}$

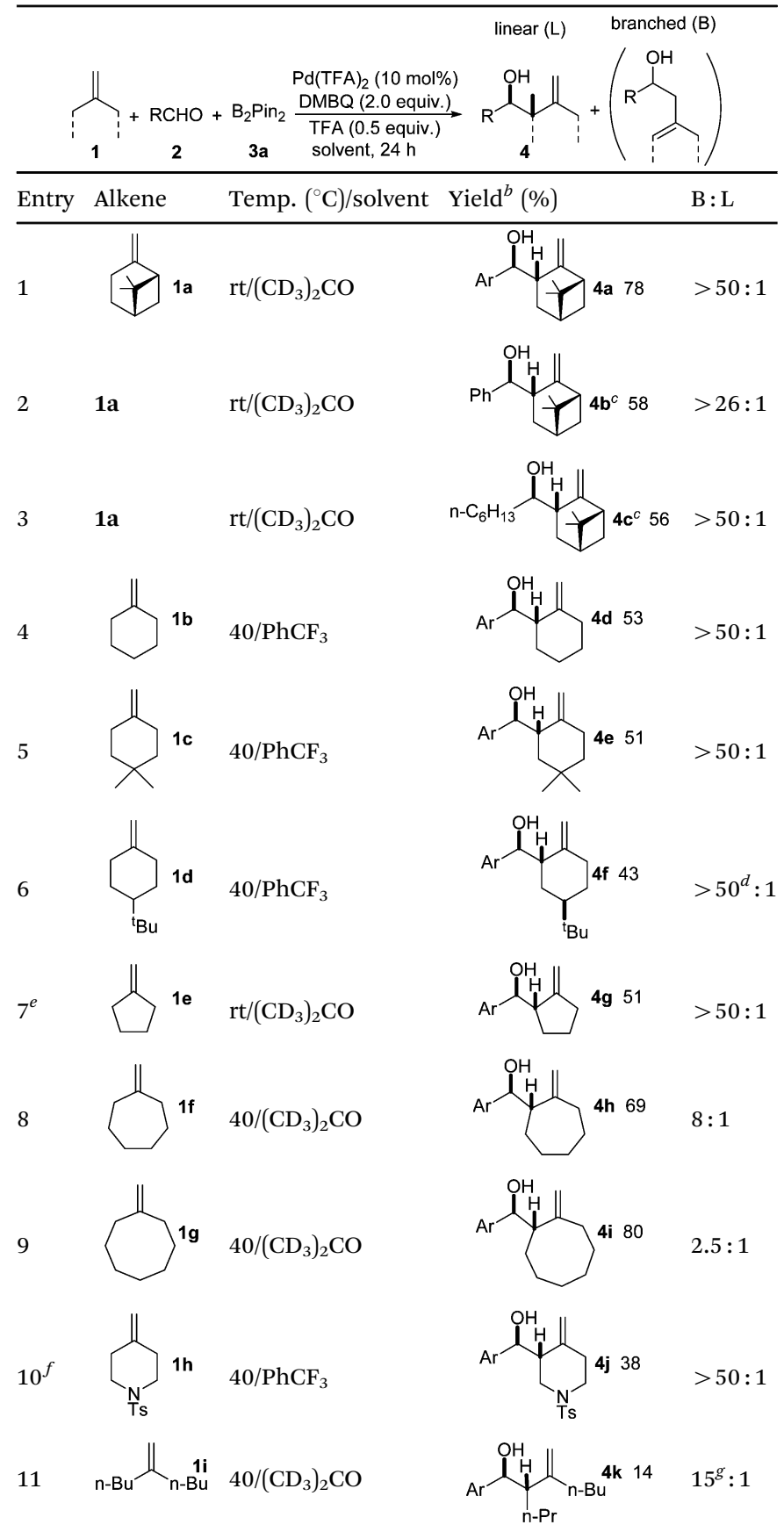

${ }^{a}$ Unless otherwise stated the reactions were carried out with 1 (0.1 mmol), 2, nitro-benzaldehyde $(0.2 \mathrm{mmol}), 3 \mathrm{a}(0.2 \mathrm{mmol})$, $\mathrm{Pd}(\mathrm{TFA})_{2}(0.01 \mathrm{mmol})$, DMBQ $(0.2 \mathrm{mmol})$ and TFA $(0.05 \mathrm{mmol})$ in solvent $(0.2-0.5 \mathrm{~mL})$ for $24 \mathrm{~h}^{b}{ }^{b}$ Isolated yields for the linear $(\mathrm{L})$ and branched (B) products together. Unless otherwise stated the branched product was isolated as a single diastereomer. ${ }^{c}$ PhCHO (entry 2) and $n$ - $\mathrm{C}_{6} \mathrm{H}_{13} \mathrm{CHO}$ (entry 3 ) were used instead of nitro-benzaldehyde. ${ }^{d}$ d.r. $=$ $9: 1 .{ }^{e}$ Tetramethyl-benzoquinone instead of DMBQ. ${ }^{f}$ Reaction was carried out with $1 \mathrm{~h}(0.2 \mathrm{mmol})$ and $2(0.1 \mathrm{mmol}) .{ }^{g}$ d.r. $=3: 2 . \mathrm{Ar}=$ 4- $\mathrm{NO}_{2} \mathrm{C}_{6} \mathrm{H}_{4}, \mathrm{DMBQ}=$ 2,6-dimethylbenzoquinone.

the reaction can be performed with diboronic acid (3b) instead of $\mathrm{B}_{2} \mathrm{pin}_{2}$ with a slight alteration of the reaction conditions (eqn (2)). This is a remarkable result, as it shows that highly oxidation 
sensitive allylboronic acids ${ }^{6}$ can also be reaction intermediates under oxidative allylic $\mathrm{C}-\mathrm{H}$ borylation conditions.

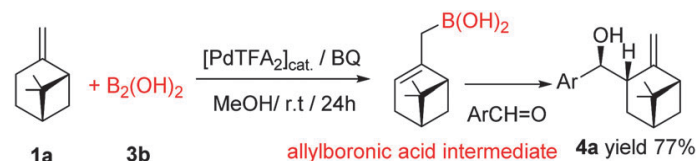

We suggest that the first step of the process is formation of allyl-palladium complex 5 by deprotonation and palladation of the allylic position of the substrate, such as $\mathbf{1 b}$ (Fig. 2). ${ }^{7}$ The subsequent step is transmetallation by $\mathrm{B}_{2} \mathrm{pin}_{2}$. It was shown that these reactions proceed easily, when weakly coordinating ligands are on $\mathrm{Pd}$. This could explain that $\mathrm{Pd}(\mathrm{TFA})_{2}$ is an excellent catalyst for the process, while $\mathrm{Pd}(\mathrm{OAc})_{2}$ with the chelating acetate group is inefficient. Iwasawa and co-workers ${ }^{9}$ have recently shown that $\mathrm{Pd}-\mathrm{Bpin}$ complexes are stable species. The reductive elimination of the Bpin group in $\mathbf{6}$ is supposed to be fast ${ }^{5}$ due to the strong trans influence of the Bpin ligand. ${ }^{10}$ It proceeds with a very high regioselectivity leading to the linear allylboronate product. This high regioselectivity is a prerequisite of the high selectivity of the allylation of aldehyde 2 affording the branched homoallylic product $4 \mathbf{d}$. The reductive elimination involves formation of $\operatorname{Pd}(0)$, which has to be reoxidized at the closing of the catalytic cycle. The main role of the used quinone is reoxidation of $\mathrm{Pd}(0)$ to $\mathrm{Pd}(\mathrm{II})$. Added trifluoroacetic acid increases the oxidation potential of the quinones and also catalyzes the allylboration of the aldehydes. ${ }^{11}$

In summary, we have shown for the first time that allylic C-H borylation can be performed with exocyclic alkenes. Multicomponent reaction involving this new $\mathrm{C}-\mathrm{H}$ borylationallylboration sequence can be performed to obtain stereodefined homoallylic alcohols. The reaction proceeds via regioselective borylation and a subsequent regio- and stereoselective allylation. The mechanistically novel element in this reaction is that it proceeds via initial formation of an allyl-palladium intermediate, which then undergoes transmetallation with $\mathrm{B}_{2} \mathrm{pin}_{2}$ and $\mathrm{a}$ subsequent regioselective reductive elimination of the allylboronate product.

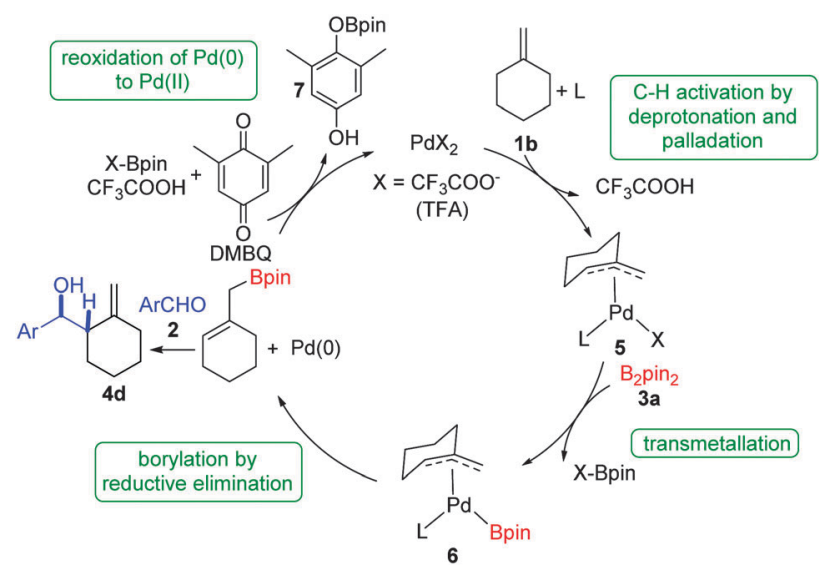

Fig. 2 Suggested catalytic cycle exemplified by substrate $\mathbf{1 b}$.
Support from the Swedish Research Council and the Knut och Alice Wallenbergs Foundation, as well as a post-doctoral fellowship for H.-P. Deng from the Wenner-Green foundation, is gratefully acknowledged. The generous gift of $\mathrm{B}_{2} \mathrm{pin}_{2}$ from Allychem is appreciated.

\section{Notes and references}

1 (a) D. G. Hall, Boronic Acids, Wiley, Weinheim, 2011; (b) I. A. I. Mkhalid, J. M. Murphy, J. H. Barnard, T. B. Marder and J. F. Hartwig, Chem. Rev., 2010, 110, 890; (c) J. F. Hartwig, Chem. Soc. Rev., 2011, 40, 1992; (d) T. Ishiyama and N. Miyaura, Pure Appl. Chem., 2006, 78, 1369.

2 (a) J.-Y. Cho, M. K. Tse, D. Holmes, R. E. Maleczka and M. R. Smith, Science, 2002, 295, 305; (b) I. I. B. A. Vanchura, S. M. Preshlock, P. C. Roosen, V. A. Kallepalli, R. J. Staples, J. R. E. Maleczka, D. A. Singleton and I. I. I. M. R. Smith, Chem. Commun., 2010, 46, 7724; (c) T. Ishiyama, J. Takagi, K. Ishida, N. Miyaura, N. R. Anastasi and J. F. Hartwig, J. Am. Chem. Soc., 2002, 124, 390; (d) T. Ishiyama, J. Takagi, J. F. Hartwig and N. Miyaura, Angew. Chem., Int. Ed., 2002, 41, 3056; (e) T. A. Boebel and J. F. Hartwig, J. Am. Chem. Soc., 2008, 130, 7534; $(f)$ D. W. Robbins, T. A. Boebel and J. F. Hartwig, J. Am. Chem. Soc., 2010, 132, 4068; $(g)$ C. C. Tzschucke, J. M. Murphy and J. F. Hartwig, Org. Lett., 2007, 9, 761; $(h)$ I. A. I. Mkhalid, D. N. Coventry, D. Albesa-Jove, A. S. Batsanov, J. A. K. Howard, R. N. Perutz and T. B. Marder, Angew. Chem., Int. Ed., 2006, 45, 489; (i) T. Ishiyama, H. Isou, T. Kikuchi and N. Miyaura, Chem. Commun., 2010, 46, 159; $(j)$ S. Kawamorita, H. Ohmiya and M. Sawamura, J. Org. Chem., 2010, 75, 3855; (k) K. Yamazaki, S. Kawamorita, H. Ohmiya and M. Sawamura, Org. Lett., 2010, 12, 3978; (l) A. Ros, R. López-Rodríguez, B. Estepa, E. Álvarez, R. Fernández and J. M. Lassaletta, J. Am. Chem. Soc., 2012, 134, 4573; (m) H.-X. Dai and J.-Q. Yu, J. Am. Chem. Soc., 2012, 134, 134; (n) B. Xiao, Y.-M. Li, Z.-J. Liu, H.-Y. Yang and Y. Fu, Chem. Commun., 2012, 48, 4854; (o) Y. Kuninobu, T. Iwanaga, T. Omura and K. Takai, Angew. Chem., Int. Ed., 2013, 52, 4431.

3 (a) I. A. I. Mkhalid, R. B. Coapes, S. N. Edes, D. N. Coventry, F. E. S. Souza, R. L. Thomas, J. J. Hall, S. W. Bi, Z. Y. Lin and T. B. Marder, Dalton Trans., 2008, 1055; (b) V. J. Olsson and K. J. Szabó, Org. Lett., 2008, 10, 3129; (c) N. Selander, B. Willy and K. J. Szabó, Angew. Chem., Int. Ed., 2010, 49, 4051; (d) T. Ohmura, Y. Takasaki, H. Furukawa and M. Suginome, Angew. Chem., Int. Ed., 2009, 48, 2372; (e) J. Takaya, N. Kirai and N. Iwasawa, J. Am. Chem. Soc., 2011, 133, 12980; $(f)$ N. Kirai, S. Iguchi, T. Ito, J. Takaya and N. Iwasawa, Bull. Chem. Soc. Jpn., 2013, 86, 784; $(g)$ A. Kondoh and T. F. Jamison, Chem. Commun., 2010, 46, 907; $(h)$ T. Kikuchi, J. Takagi, H. Isou, T. Ishiyama and N. Miyaura, Chem. - Asian J., 2008, 3, 2082; (i) T. Kikuchi, J. Takagi, T. Ishiyama and N. Miyaura, Chem. Lett., 2008, 37, 664; $(j)$ I. Sasaki, H. Doi, T. Hashimoto, T. Kikuchi, H. Ito and T. Ishiyama, Chem. Commun., 2013, 49, 7546. 4 (a) A. Caballero and S. Sabo-Etienne, Organometallics, 2007, 26, 1191; (b) V. J. Olsson and K. J. Szabo, Angew. Chem., Int. Ed., 2007, 46, 6891; (c) V. J. Olsson and K. J. Szabó, J. Org. Chem., 2009, 74, 7715; (d) H. Y. Chen, S. Schlecht, T. C. Semple and J. F. Hartwig, Science, 2000, 287, 1995; (e) J. M. Murphy, J. D. Lawrence, K. Kawamura, C. Incarvito and J. F. Hartwig, J. Am. Chem. Soc., 2006, 128, 13684; $(f)$ C. W. Liskey and J. F. Hartwig, J. Am. Chem. Soc., 2012, 134, 12422; $(g)$ C. W. Liskey and J. F. Hartwig, J. Am. Chem. Soc., 2013, 135, 3375; (h) S. H. Cho and J. F. Hartwig, J. Am. Chem. Soc., 2013, 135, 8157; (i) T. A. Boebel and J. F. Hartwig, Organometallics, 2008, 27, 6013; $(j)$ S. Shimada, A. S. Batsanov, J. A. K. Howard and T. B. Marder, Angew. Chem., Int. Ed., 2001, 40, 2168; (k) T. Ishiyama, K. Ishida, J. Takagi and N. Miyaura, Chem. Lett., 2001, 1082; (l) T. Ohmura, T. Torigoe and M. Suginome, J. Am. Chem. Soc., 2012, 134, 17416; $(m)$ T. Ohmura, T. Torigoe and M. Suginome, Organometallics, 2013, 32, 6170; (n) T. Ohmura, T. Torigoe and M. Suginome, Chem. Commun., 2014, 50, 6333; (o) S. Kawamorita, T. Miyazaki, T. Iwai, H. Ohmiya and M. Sawamura, J. Am. Chem. Soc., 2012, 134, 12924; (p) S. Kawamorita, R. Murakami, T. Iwai and M. Sawamura, J. Am. Chem. Soc., 2013, 135, 2947; $(q)$ T. Mita, Y. Ikeda, K. Michigami and Y. Sato, Chem. Commun., 2013, 49, 5601. 
5 J. M. Larsson and K. J. Szabó, J. Am. Chem. Soc., 2013, 135, 443. 6 M. Raducan, R. Alam and K. J. Szabó, Angew. Chem., Int. Ed., 2012, 51, 13050.

7 B. M. Trost, P. E. Strege, L. Weber, T. J. Fullerton and T. J. Dietsche, J. Am. Chem. Soc., 1978, 100, 3407.

8 K. J. Szabó, in Science of Synthesis Reference Library: Multicomponent Reactions, ed. T. J. J. Müller, Thieme, Stuttgart, 2013, p. 345.
9 N. Kirai, J. Takaya and N. Iwasawa, J. Am. Chem. Soc., 2013, 135, 2493. 10 J. Zhu, Z. Lin and T. B. Marder, Inorg. Chem., 2005, 44, 9384.

11 (a) V. Rauniyar and D. G. Hall, Angew. Chem., Int. Ed., 2006, 45, 2426; (b) S. H. Yu, M. J. Ferguson, R. McDonald and D. G. Hall, J. Am. Chem. Soc., 2005, 127, 12808; (c) N. Selander, S. Sebelius, C. Estay and K. J. Szabó, Eur. J. Org. Chem., 2006, 4085; (d) N. Selander, A. Kipke, S. Sebelius and K. J. Szabó, J. Am. Chem. Soc., 2007, 129, 13723. 